\title{
Serotonergic hyperactivity as a potential factor in developmental, acquired and drug-induced synesthesia
}

\author{
Berit Brogaard* \\ Department of Philosophy and Center for Neurodynamics, University of Missouri, St. Louis, MO, USA
}

\section{Edited by:}

Beat Meier, University of Bern,

Switzerland

Reviewed by:

Devin Terhune, University of Oxford, United Kingdom

David Brang, Northwestern

University, USA

*Correspondence:

Berit Brogaard, Department of Philosophy and Center for

Neurodynamics, University of Missouri, St. Louis, MO 63121, USA

e-mail: brogaardb@gmail.com
Though synesthesia research has seen a huge growth in recent decades, and tremendous progress has been made in terms of understanding the mechanism and cause of synesthesia, we are still left mostly in the dark when it comes to the mechanistic commonalities (if any) among developmental, acquired and drug-induced synesthesia. We know that many forms of synesthesia involve aberrant structural or functional brain connectivity. Proposed mechanisms include direct projection and disinhibited feedback mechanisms, in which information from two otherwise structurally or functionally separate brain regions mix. We also know that synesthesia sometimes runs in families. However, it is unclear what causes its onset. Studies of psychedelic drugs, such as psilocybin, LSD and mescaline, reveal that exposure to these drugs can induce synesthesia. One neurotransmitter suspected to be central to the perceptual changes is serotonin. Excessive serotonin in the brain may cause many of the characteristics of psychedelic intoxication. Excessive serotonin levels may also play a role in synesthesia acquired after brain injury. In brain injury sudden cell death floods local brain regions with serotonin and glutamate. This neurotransmitter flooding could perhaps result in unusual feature binding. Finally, developmental synesthesia that occurs in individuals with autism may be a result of alterations in the serotonergic system, leading to a blockage of regular gating mechanisms. I conclude on these grounds that one commonality among at least some cases of acquired, developmental and drug-induced synesthesia may be the presence of excessive levels of serotonin, which increases the excitability and connectedness of sensory brain regions.

Keywords: acquired synesthesia, autism spectrum disorder, drug-induced synaesthesia, left-hemisphere injuries, multisensory perception, savant syndrome, serotonin hypothesis, traumatic brain injury

\section{INTRODUCTION}

Synesthesia is an extraordinary way of perceiving the world, involving experiences of connections between seemingly unrelated sensations, images or thoughts (Baron-Cohen et al., 1987; Cytowic, 1989; Rich and Mattingley, 2002; Sagiv and Ward, 2006; Brogaard, 2012). For example, seeing the number 7 may lead to an experience of navy blue, hearing the word "bliss" may flood the mouth with the flavor of bread soaked in tomato soup and hearing the key of $\mathrm{C \#}$ minor may elicit a bright purple spiral radiating from the center of the visual field. The trigger of the experience is called "the inducer," whereas the additional experience to which it gives rise is called "the concurrent" (Grossenbacher and Lovelace, 2001). In visual synesthesia, the concurrent may be projected out into space and experienced as located in the visual scene outside the subject's mind, or it may be merely imagistically or semantically associated with the inducer (Dixon et al., 2004).

The two key characteristics of synesthesia regardless of whether it is of the projector or associator type is that it involves an aberrant binding of features from different sensory or cognitive streams that are associated with atypical conscious experiences or thoughts and that these experiences or thoughts are automatic, that is, synesthetes cannot suppress the association between an inducer and its concurrent. Other characteristics of the condition are specific to the different forms. According to Grossenbacher and Lovelace (2001), there are three different types of synesthesia:

(1) Developmental, or genuine, synesthesia

(2) Acquired synesthesia

(3) Drug-induced synesthesia

Developmental synesthesia, the most common type, is a form of the condition that has persisted since birth or early childhood and that remains relatively stable and systematic over time: each inducer has a highly specific concurrent. (Baron-Cohen et al., 1987; Mattingley et al., 2001; Simner et al., 2006). It also tends to run in families (Baron-Cohen et al., 1996). For the most common forms of developmental synesthesia, the Synesthesia Battery, an automated online test, allows for rigorous testing of both the tightness of the synesthetic association and its stability and systematicity over time (www.synaesthete.org; Eagleman et al., 2007).

Acquired synesthesia is a form of the condition that emerges after brain injury or disease or artificial technologies like sensory substitution (Ward and Wright, 2012). It has been reported following stroke (Ro etal., 2007; Beauchamp and Ro, 2008; Thomas-Anterion et al., 2010; Schott, 2012), traumatic brain injury (Brogaard et al., 2012; Brogaard and Marlow, 2013), neuropathology involving the optic nerve and/or chiasm (Jacobs et al., 
1981; Armel and Ramachandran, 1999; Afra et al., 2009), seizures (Jacome and Gumnit, 1979), migraine (Alstadhaug and Benjaminsen, 2010), post-hypnotic suggestion (Cohen Kadosh et al., 2009) and sensory substitution (Ward and Wright, 2012). Audiovisual synesthesia has been reported to be the most common acquired type (Afra et al., 2009). Like developmental synesthesia, acquired synesthesia tends to be automatic and systematic over time, though in some cases it only persists for a limited time period (Jacome and Gumnit, 1979; Lessell and Cohen, 1979; Afra et al., 2009). Experientally, acquired synesthesia may be indistinguishable from developmental synesthesia, though it is sometimes less inducer-specific, that is, the same concurrent may have several different inducers (Brogaard et al., 2012). Cases have also been reported in which the acquired experience is simpler than the developmental counterpart, often similar to light flashes (phosphenes) or pure color experiences (Afra et al., 2009).

Drug-induced synesthesia is a blending of sensory or cognitive streams that is experienced during exposure to a hallucinogen (psilocybin, LSD, mescaline, peyote; Shanon, 2002; Friedrichs, 2009; Sinke et al., 2012). Unlike the developmental and acquired varieties, the drug-induced form is usually limited to the most intense phases of intoxication, though in some cases it continues for weeks or months after exposure to the drug (Abraham, 1983; Ffytche, 2007). Experientally, drug-induced synesthesia can vary from simple color experiences to complex, surrealistic landscapes consisting of, for example, oddly shaped objects with multicolored contours or images with ornamental or kaleidoscopic compositions (Hintzen and Passie, 2010).

Though synesthesia research has seen a huge growth in recent decades, and tremendous progress has been made in terms of understanding the mechanism and cause of the condition, we are still left mostly in the dark when it comes to the mechanistic commonalities (if any) among developmental, acquired and drug-induced synesthesia. It is widely believed that most forms of the condition involve functional or structural aberrant brain connectivity. The proposed mechanisms include direct or indirect projection through increased structural connectivity (Ramachandran and Hubbard, 2001a,b; Hubbard etal., 2005; Rouw and Scholte, 2007; Jancke et al., 2009; Hanggi etal., 2011; Zamm etal., 2013), functionally driven disinhibited-feedback mechanisms (Grossenbacher and Lovelace, 2001; Dixon etal., 2006; Esterman etal., 2006; Neufeld et al., 2012), and mixed models (Hubbard, 2007; Ward, 2013). However, it is unclear what causes the onset of the condition and whether the different types of synesthesia have different causes.

One proposal by Brang and Ramachandran (2007) suggests serotonin (5-HT) as a causal factor. Their specific suggestion is that "serotonin S2a receptors are the 'synesthesia receptors' in the brain" (p. 903). In support of this hypothesis they list four pieces of evidence: (i) LSD produces synesthesia by selectively activating serotonin 5-HT2A receptors. (ii) Prozac (fluoxetine), a selective serotonin reuptake inhibitor that increases 5-HT1 receptor activity thereby inhibiting 5-HT2A, blocked synesthesia in two subjects. (iii) the anxiolytic drug Wellbutrin (bupropion), which presumably inhibits 5-HT2A receptor activity, temporarily abolished synesthesia in one subject, (iv) melatonin, a brain hormone derived from serotonin that can disinhibit 5-HT2A receptor activity, temporarily induced grapheme-color synesthesia in a subject with number-form synesthesia.

Thus, Brang and Ramachandran's (2007) suggestion is that serotonin may be functionally implicated in generating synesthetic experience through 5-HT2A receptor activity. In the formulation of the hypothesis Brang and Ramachandran (2007) do not specify which of the 5-HT2A receptors in the brain cause synesthesia, whether the serotonin receptors that are "synesthesia receptors" are inhibitory or excitatory, whether serotonin could be structurally implicated in causing synesthesia through altered structural connectivity during brain development and whether the serotonin hypothesis may also explain cases of acquired synesthesia. My aim in this paper is to develop the serotonin hypothesis to tentatively answer these questions by looking at a wider range of evidence.

More specifically, my proposal is that excessive extracellular serotonin (5-HT) can be a trigger of persistent or transient synesthesia in all the groups through excitatory mechanisms. Though serotonin traditionally has been considered an inhibitory neurotransmitter, more recent evidence suggests a more complex picture according to which serotonin can function both as an inhibitory and an excitatory neurotransmitter. For example, serotonin helps reduce fear processing in the amygdala via GABA modulation but it exerts an excitatory effect on cortical brain activity when it binds to 5-HT2A serotonin receptors on layer V pyramidal neurons (Barkai and Hasselmo, 1994; Aghajanian and Marek, 1999).

As indicated by Brang and Ramachandran (2007), the suggestion that serotonergic activity may be a trigger of synesthesia has the greatest degree of evidential backing in the case of druginduced synesthesia. It has been shown in several studies that psychedelic hallucinogens that function primarily as serotonin agonists, such as psilocybin, LSD and mescaline, often induce transient, often auditory-visual synesthesia, presumably through an alteration of functional brain connectivity. Though not all serotonin agonists elicit synesthetic experience, it is widely agreed that the mechanism of action for the class of serotonergic hallucinogens is through binding of serotonin to the 5-HT2A serotonin receptor (Presti and Nichols, 2004; González-Maeso et al., 2007).

Excessive serotonin levels may also play a role in synesthesia acquired after brain injury. Research has shown that necrosis following tissue damage leads to local neurotransmitter flooding caused by an excessive release of serotonin and glutamate (Busto et al., 1997; Hinzman et al., 2010), a phenomenon that can have long-range consequences even when the injury is minor. This flooding appears to lead to increased functional or structural interconnectedness among different brain regions in some individuals, and in some cases this increased connectivity may be a cause of synesthesia.

Developmental synesthesia has been reported as a condition in autism-spectrum disorders (Ornitz et al., 1978; Grandin, 1995; Kemner et al., 1995; Harrison and Hare, 2004; Asher et al., 2009; Baron-Cohen et al., 2009), and is believed to be more frequently occurring in individuals with autism compared to the general population (Cytowic, 1989). It is suggested below that synesthesia accompanying autism may be a serotonergic condition, resulting 
from excessive serotonin levels in early childhood that could possibly lead to decreased extracellular levels of serotonin in one hemisphere and compensatory increased levels in the other hemisphere. One piece of evidence for this comes from PET scans of people with high-functioning autism which have revealed that in the majority of cases serotonin synthesis is suppressed in the left hemisphere and increased in the right hemisphere, though in some cases it is reversed (Chandana et al., 2005). Recent genetic studies furthermore suggest a genetic link between autism spectrum disorder and developmental synesthesia in non-autistic individuals (Asher et al., 2009). Whether there is a mechanistic link between autism and cases of developmental synesthesia in non-autistic individuals remains to be established.

In what follows I will provide detailed evidence for the hypothesis that one commonality among at least some cases of acquired, developmental and drug-induced synesthesia is the presence of excessive levels of serotonin or serotonin-agonists, which increase the excitability and connectedness of sensory brain regions through 5-HT2A receptors in cortical neurons.

\section{ACQUIRED SYNESTHESIA}

The acquired form of synesthesia usually emerges subsequent to traumatic brain injury or neuropathologic insult to the brain (Beauchamp and Ro, 2008; Afra et al., 2009; Brogaard et al., 2012). Several studies have hypothesized that these acquired synesthesias occur from plasticity of the sensory systems resulting in increased connectivity (Ro et al., 2007; Beauchamp and Ro, 2008). This theory has additionally been studied in at least one case of acquired synesthesia (Ro et al., 2012). Ro et al. (2012) found that connections between the auditory and somatosensory cortices in healthy controls were strengthened in a subject with auditory-tactile synesthesia acquired after a right ventrolateral thalamic lesion that deprived her somatosensory cortex of normal somatosensory input.

It remains largely unknown how a brain lesion may give rise to the plastic changes that lead to the increased connectivity. One possibility is that it is caused by increased neurotransmitter activity in cortical regions adjacent to the affected site. This increase is believed to contribute to the pathophysiology and neurological dysfunction after traumatic brain injury (Busto et al., 1997; Bullock et al., 1998; Robertson et al., 2001; Werner and Engelhard, 2007; Hinzman et al., 2010). In traumatic brain injury tissue damage makes the cells shift to anaerobic glycolysis, resulting in an accumulation of lactic acid. The anaerobic metabolism cannot by itself maintain the energy levels, so ATPstores are depleted and the membrane ion-pumps, which depend on ATP, fail. This leads to membrane degradation of vascular and cellular structures and necrotic or programmed cell death (apoptosis), resulting in excessive release of excitatory neurotransmitters, particularly serotonin and glutamate (Busto et al., 1997; Hinzman etal., 2010). This excess in extracellular serotonin and glutamate availability affects neurons and astrocytes and results in over-stimulation of serotonin and glutamate receptors. It is believed that this over-stimulation effect can happen even in mild traumatic brain injury, as the release of neurotransmitters is vast even with minor lesions (Konrad et al., 2011; Perez-Polo et al., 2013). Other types of brain injury that have been reported to trigger synesthesia, such as stroke (Ro et al., 2007; Beauchamp and Ro, 2008; Afra et al., 2009; Thomas-Anterion et al., 2010; Schott, 2012), also cause neurotransmitter flooding after necrosis. It has been found, for example, that even a brief ischemic stroke may trigger complex biochemical events that lead to progressive apoptotic and necrotic neuronal cell death (Yuan, 2009).

The increased levels of serotonin and glutamate immediately following brain injury do not normally stay elevated for very long (Eysel et al., 1999). Eysel et al. (1999) induced 1.5 to $2 \mathrm{~mm}$ lesions in the striate cortex of cats using surface photocoagulation or ibotenic acid injections. Single cell measurements revealed that activity was decreased at the border of the lesion and increased in a ring around the lesion during the first days to weeks following the induction but it returned to normal after about a month (Eysel et al., 1999). Despite the fact that serotonin does not seem to stay elevated for more than one month following a brain lesion, there is suggestive evidence that the temporary elevation may suffice for creating long-lasting functional, and possibly also structural, changes (Giza and Prins, 2006; Konrad et al., 2011; Perez-Polo et al., 2013). It has furthermore been reported that initial increases in neurotransmitter levels following brain injury or disease may be followed by down-regulation of receptors in ipsilateral brain regions (Giza and Prins, 2006).

One hypothesis for how brain injury or disease may cause synesthesia, then, is that the initially elevated neurotransmitter levels down-regulate serotonin receptors in neural regions in the ipsilateral hemisphere, leading to decreased serotonin levels. Individuals who acquire synesthesia also sometimes develop autistic traits and savant-like abilities of the sort seen in 10 percent of autistic individuals (Baron-Cohen et al., 2007; Treffert, 2009; Brang and Ramachandran, 2011; Rogowska, 2011; Brogaard et al., 2012; Schott, 2012; Ward, 2013). Emerging savant skills have also been reported in many other cases of central nervous system injury or disease later in life (Fay, 1987; Dorman, 1991; Miller et al., 1998, 2000; Lythgoe et al., 2005; Tammet, 2006; Treffert, 2006, 2009; Snyder, 2009). As is known from studies of autistic savants, downregulation of the serotonergic system in one hemisphere may result in an upregulation of the serotonergic system in contralateral brain regions (DeLong, 1999; Takeuchi et al., 2012), which might explain the development of savant skill and synesthesia following brain injury (Treffert, 2009). A second hypothesis is that the elevation in serotonin and glutamate levels in the days or weeks after brain injury can trigger disinhibited feedback or a structural binding of features through serotonergic hyperactivity in sensory neurons or neurons in parietal cortex involved in mental imagery. The latter have been found to be plausible neural correlates in at least one case of acquired synesthesia (Brogaard et al., 2012).

The second hypothesis is more plausible than the first when synesthesia is acquired after brain injury. It would explain the increased ipsilateral connectivity found in at least one case of acquired synesthesia (Ro et al., 2012). It gains further support from the fact that the onset of synesthesia following brain injury has been reported to occur shortly after the injury rather than months later, which indicates that it is the initial neurotransmitter flooding that causes the onset. Furthermore, if the first 
hypothesis were correct, then the affected region would have to be crucially implicated if the down-regulation triggers an upregulation in other areas, an assumption that cannot be confirmed at the present time. The first hypothesis may have a greater degree of support for synesthesia acquired after frontotemporal dementia. Cell death in frontotemporal dementia does not normally occur via necrosis that leads to neurotransmitter flooding. However, it is well known that patients with this condition have deficits in serotonergic and dopaminergic signal-transmission. These deficits may account for some of the cognitive and behavioral impairments of the disease. As prefrontal areas are known to exert inhibitory control over other brain regions, decreased activity in these neural regions could lead to a disinhibitory enhancement of neural activity and connectivity in unaffected cortical regions (DeLong, 1999; Treffert, 2009), which could also explain why this type of dementia frequently is reported as a cause of savant skills (Miller et al., 2000). Regardless of whether the synesthesia is acquired after brain injury or dementia, neuroimaging might help reveal whether the unusual binding is functional or structural. For example, if it is functional, we should expect to find increased connectivity in functional connectivity analyses on fMRI data.

The above considerations raise the question of why only a small fraction of brain injury patients acquire synesthesia-like experiences. One possible answer is that individual differences originate in variance in the degree of plasticity of the subject's brain prior to the incident. Research on brain injury in children has shown that alterations in neurotransmission during the critical period when a brain region is most plastic can promote outgrowth of abnormal neural connections (Giza and Prins, 2006). Since it is likely that there are significant individual differences in the plasticity of the mature brain, it is possible that some subjects are more susceptible to the formation of new neural connections than others. Individual differences are no doubt also grounded in variance in the location of the injury. Synesthesia-like experiences may be much more likely to develop if sensory regions or neural areas implicated in mental imagery are affected.

Given the broad range of conditions that can trigger acquired synesthesia it is unlikely that there is a single mechanism underlying all cases. Some cases appear to be quite similar in persistence and phenomenology to well-known forms of developmental synesthesia and are likely to share a neurological basis with some of these varieties of synesthesia. For example, autistic savant Daniel Tammet describes in his book Born on a Blue Day that he acquired synesthesia after childhood seizures. Though his grapheme-color synesthesia appears unusually rich, it may have neurological underpinnings akin to more typical developmental forms. Other forms of acquired synesthesia appear to be transient and may well be a more direct product of excitatory neural activity, similar in many respects to synesthetic experience occurring under the influence of hallucinogens (see below). An example would be synesthesia experienced during occipital and temporal lobe seizures, which can lead to brief experiences quite similar to psychedelic experiences (Devinsky and Luciano, 1991; Cytowic, 1997; Sacks, 2012). Some forms of acquired synesthesia could be undergird by a different mechanism not typically found after drug intoxication or aberrant neural development. In cases in which synesthesia and savant syndrome are acquired in the same incident, the two conditions may well be triggered in similar ways. This could be the case for Tammet, who reports having synesthesia matching not only digits but also the product of digits. His synesthesia could possibly be an imagistic manifestation of number processing in the parietal cortex. One observation that supports this hypothesis is that the lack of increased activity in the visual cortex in response to synesthetic tasks found in an imaging study comparing brain activity in Tammet and controls (Bor et al., 2007). But more research needs to be done to settle these questions. In most cases of acquired synesthesia the research component has taken place several years after the onset of the condition. If we could perform the research (e.g., neuroimagining studies) closer to the onset, we might be able to determine whether serotonergic hyperactivity in sensory neurons is implicated in the sudden, unusual binding of features.

\section{DRUG-INDUCED SYNESTHESIA}

Drug-induced synesthesia is a blending of perceptual or cognitive streams that emerges in subjects under the influence of psychedelic hallucinogens, psychoactive substances that alter perception, mood, and a variety of cognitive processes. A myriad of first-person reports indicate that synesthesia occurs during psychedelic intoxication. Some reports suggest an altered perception of the world that blends normally distinct senses. Reports of colored music are particularly frequent (Shanon, 2002, 2003; Sinke et al., 2012). In other cases external objects appear to the perceiver as having an unusual wealth of colors, textures and shapes that undergo rapid changes. Subjects report seeing melting windows, breathing walls and spiraling geometrical figures crawling over the surfaces of objects. Reflecting on a DMT session one subject, described by Cott and Rock (2008), reported that "The room erupted in incredible neon colors, and dissolving into the most elaborate incredibly detailed fractal patterns that I have ever seen." The authors characterize this as a hallucination, and it is admittedly difficult to distinguish synesthesia and hallucinations, particularly because some forms of synesthesia probably are best characterized as hallucinations (Sagiv et al., 2011). A crucial difference seems to be that hallucinations proper do not have a phenomenally apparent inducer, whereas synesthesia does. Another difference is that most forms of synesthesia are experienced as endogenous images or representations (i.e., associator synesthesia, Dixon et al., 2004). Yet another difference is that synesthetes know that the concurrent experience is not a veridical perception, whereas hallucinations tend to evoke the experience of the veridicality of the perception (Terhune and Cohen Kadosh, 2012).

It is by now fairly well established that two major classes of psychedelic hallucinogens, the indoleamines (e.g., LSD and psilocybin) and the phenethylamines (e.g., mescaline), are potent partial agonists at serotonin $5-\mathrm{HT} 1 \mathrm{~A} / 2 \mathrm{~A} / 2 \mathrm{C}$ receptors, with 5$\mathrm{HT} 2 \mathrm{~A}$ receptor activation directly correlated with hallucinogenic activity (Glennon, 1990; Vollenweider et al., 1998; Nichols, 2004; Presti and Nichols, 2004; though see e.g., Previc, 2011 for a different perspective). Though the mechanism of action varies for different hallucinogens, it is believed that 5-HT2A receptor activation of cortical neurons is responsible for mediating the 
signaling pattern and behavioral response to hallucinogens (Presti and Nichols, 2004; González-Maeso et al., 2007). However, the activation of the cortical serotonergic system does not fully explain the perceptual effects of psychedelic drugs, as not all 5-HT2A agonists (or partial agonists) have an excitatory mechanism of action and not all 5-HT2A agonists have psychedelic effects (e.g., methysergide). So, this raises the question of what other factors need to be present for drug-induced hallucinations to occur.

A promising suggestion for how the hallucinatory effects occur is that hallucinogens activate layer $\mathrm{V}$ pyramidal neurons in the cortex, which engage in gating functions in communication between the cortex and subcortical brain regions (Barkai and Hasselmo, 1994). When a hallucinogen binds to the 5-HT2A receptor, this gives rise to an excitatory response (Scruggs et al., 2003; Nichols, 2004). Recent research suggests that co-transmission of glutamate and monoamines is a frequent occurrence in the central nervous system (Trudeau, 2004; Ciranna, 2006). The 5-HT2A receptors, specifically, have been found to increase glutamate release (Ceglia et al., 2004; Torres-Escalante et al., 2004). There is furthermore evidence suggesting that the hallucinogen psilocybin targets a cortical receptor complex that forms when the glutamate mGluR2 receptor interacts with the serotonin 5-HT2A receptor (González-Maeso et al., 2008). Increased release of glutamate in response to hallucinogen administration should enhance cortical metabolic activity, a finding that has been confirmed by Vollenweider et al. (1997). Perceptual changes have been found to correlate with increased metabolic activity in the frontomedial and frontolateral cortices, anterior cingulate, and temporomedial cortex (Vollenweider et al., 1997). There is also some evidence from EEG studies that activation of 5-HT2A receptors increases the excitability of cortical sensory networks by modulating alpha oscillations (8-12 Hz; Kometer et al., 2013). Brain waves in the alpha frequency range have been shown to regulate the excitability levels of cortical sensory networks through inhibition (Klimesch, 2011). The increased excitatory action of serotonin and glutamate in sensory regions might explain why hallucinogens mimic aspects of psychosis during intoxication (Aghajanian and Marek, 1999; Pralong et al., 2002; Nichols, 2004; González-Maeso et al., 2008).

The view that the hallucinatory effects of hallucinogens are primarily a result of enhanced neural activity may appear inconsistent with a recent fMRI study showing that psilocybin causes decreased activity in the ACC/medial prefrontal cortex and a significant decrease in the positive coupling between the medial prefrontal cortex and the posterior cingulate cortex, and that these findings were correlated with subjective effects (Carhart-Harris et al., 2012). As Lee and Roth (2012) point out, however, these results are consistent with the observation that 5-HT2A receptors are found on both layer $\mathrm{V}$ glutamatergic neurons and GABAergic interneurons. Furthermore, there is also a direct activation of GABAergic interneurons through the synapses of pyramidal cells onto the interneurons (Markram et al., 2004). So, a large excitatory response in a pyramidal neuron will lead to a large inhibitory response in the interneuron. Lee and Roth (2012) propose that the effects of psilocybin could be due to both excitatory (e.g., pyramidal) and inhibitory (e.g., GABAergic interneuronal) neuronal circuits and that it may be the effects on the inhibitory neuronal circuits that gave rise to the measured BOLD response (see Figure 1).

To my knowledge, no model of how hallucinogens trigger synesthesia has yet been proposed. One natural proposal would be that the mechanisms in developmental and drug-induced synesthesia are similar. There is, however, some reason to doubt this suggestion. The phenomenological differences between developmental and drug-induced synesthesia are quite striking (see Sinke et al., 2012 for a review). As experiences causally supervene on neurological processes, experiences that are significantly different in their phenomenology are bound to have significantly different neurological underpinnings. So, we should expect some differences in the underlying mechanisms.

One tentative suggestion is that drug-induced synesthesia, like hallucinations, originates in the hyperactivity of layer $\mathrm{V}$ pyramidal cells resulting from the binding of hallucinogens to 5-HT2A receptors in the cells' dendrites, which then increases local glutamate levels. Layer $\mathrm{V}$ pyramidal cells bind multisensory information through feedback loops that synchronize oscillatory neural responses (Guillery and Harting, 2003). In the visual and the auditory cortices layer $\mathrm{V}$ neurons form feedback loops with local neurons as well as neurons in the thalamus and prefrontal cortex. Projections to thalamus play a role in discriminating among incoming information and integrating information from different sensory channels, whereas projections to the prefrontal cortex play a role in higher-order processes and the generation of a conscious representation. In normal multisensory perception, low-level multisensory binding of incoming signals from visual and auditory channels occurs spontaneously in the auditory cortex via thalamocortical feedback loops, when the spatial and temporal attributes of incoming signals match (Schroeder

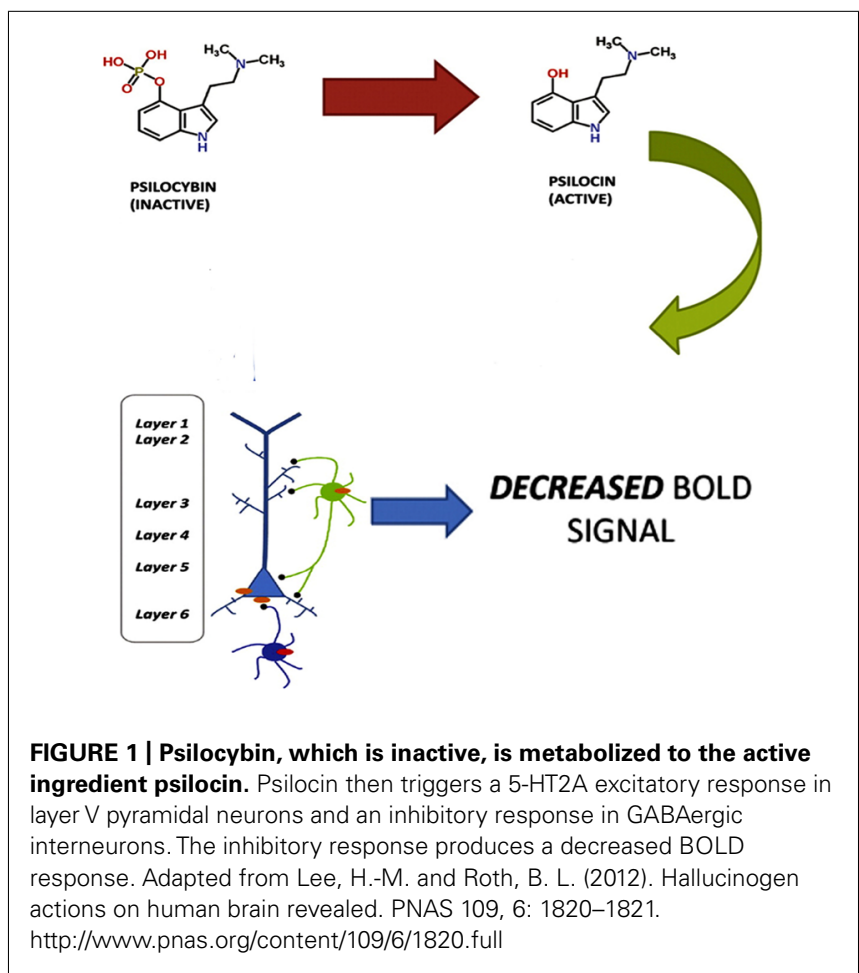


and Foxe, 2005). Excessive excitatory activity in layer V pyramidal neurons, however, results in a destabilization of layer $\mathrm{V}$ projections to the thalamus through GABAergic neuronal circuits (Kim and McCormick, 1998; Markram et al., 2004). This has a number of consequences, such as decreased attentional discrimination among incoming stimuli, allowing more information to flood the sensory cortices, a loss of stimulus-specific inhibition, an resultant increase of random (or environmentally under-constrained) activity in the thalamus, and a disruption of low-level, spontaneous integration of multisensory stimuli on the basis of actually matching spatial and temporal attributes. The disruption of low-level integration mechanisms can result in incongruent experiences, such as hearing an object hit the floor prior to seeing it fall. Another result of this disruption of low-level integration may be a coupling of stimuli that do not belong together. A common synesthetic experience during hallucinogen intoxication is colored, geometrical grids, matrices or fractals induced by music (see Sinke et al., 2012 for a review). These types of visual experience also frequently occur without an inducer, probably as a result of random activity in the thalamus (Behrendt and Young, 2004; Sagiv et al., 2011). One possible mechanism for drug-induced synesthesia, then, is that the brain assumes that an experience that results from occipital processing of random thalamic activity matches auditory stimuli, leading to an unusual low-level binding in the auditory cortex (see Figure 2). As a result of this aberrant binding, the two inputs may be experienced as an inducer-concurrent pair, for example colored, geometrical music.
The proposed mechanism leads to the testable prediction that drug-induced synesthesia will not usually be systematic. In developmental cases sound-color synesthesia is systematic in the sense that very specific sounds normally trigger very specific colors. Given the aberrant binding proposed, however, it appears that drug-induced sound-color synesthesia will not tend to be systematic because random activity will be paired with available auditory information. So, we should expect that the same sound may have many different colors and shapes.

There are only few reports of drug-induced synesthesia that endures post-exposure, though there is evidence that other practices that can induce altered states of consciousness, such as meditation and posthypnotic suggestion, frequently cause enduring synesthesia (Walsh, 2005; Cohen Kadosh et al., 2009). The suggested mechanism may help explain why drug-induced synesthesia is seldom persistent over time. The hypothesis proposed is that occipitally processed random activity is coupled with available auditory information during drug-induction. The random activity does not persist in the same magnitude after drug exposure, which may explain why the synesthetic experiences and hallucinations tend to subside. But what further decreases the chance that the synesthesia persists would be the lack of a one-one mapping or even a many-one mapping from inducer to concurrent, which we might expect will make the unusual synesthetic binding less likely to be retained as a neural connection.

The proposed mechanism of hyperexcitability followed by disruption may appear to be inconsistent with a related finding for
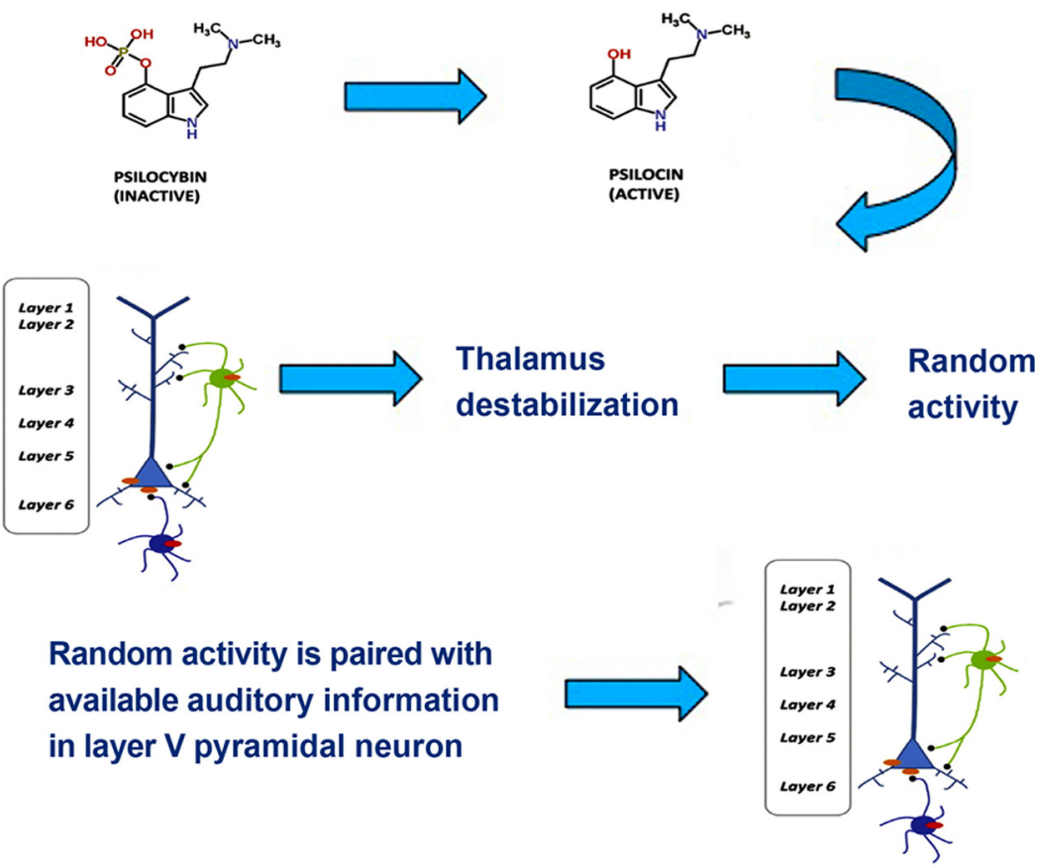

FIGURE 2 | Psilocybin, which is inactive, is metabolized to the active ingredient psilocin. Psilocin then triggers a 5-HT2A excitability response in layer $V$ pyramidal neurons and an inhibitory response in GABAergic interneurons. This leads to thalamic destabilization, which triggers random thalamic activity. The occipitally processed random activity is paired with available auditory information in layer $\mathrm{V}$ pyramidal neurons, which yields synesthetic experience. Adapted from Figure 1 
developmental synesthesia. It is believed that enhanced cortical excitability at an early developmental stage might contribute to atypical grapheme-color binding, even though it does not appear to be a direct cause of synesthesia at later stages (Asher et al., 2009; Tomson etal., 2011). A recent study reported data that were consistent with the idea that at later stages the hyperexcitability can hinder synesthesia by producing excess noise in the visual cortex and thereby reducing conscious awareness of the atypical binding of features (Terhune et al., 2011). However, I think that this suggestion can be reconciled with the proposed mechanism for drug-induced synesthesia. It is plausible that hyperexcitability may no longer play a functional role at later stages of developmental synesthesia (Terhune et al., 2011). Hallucinogenic serotonin agonists, however, appear to introduce a significant amount of hyperexcitability that can offset normal binding by disrupting low-level integration mechanisms. It is possible that some varieties of developmental synesthesia form in early childhood in a way similar to the way druginduced synesthesia is here hypothesized to form temporarily later in life, but there would be certain differences: developmental synesthesia is systematic so if synesthesia develops in childhood as a result of a disruption of low-level integration, it is not a result of random activity in the thalamus. Furthermore, the presence of the hyperexcitability during brain development must somehow make it more likely that the unusual binding persists over time than when the hyperexcitability is drug-induced.

A version of the proposed model also appears consistent with the findings of Cohen Kadosh et al. (2009). The team induced strong projector grapheme-color synesthesia using posthypnotic suggestion in a group of highly suggestible college students. In most cases the synesthesia was found to endure and to display the phenomenal characteristics of developmental grapheme-color synesthesia. Cohen Kadosh et al. (2009) provide evidence suggesting that the induced synesthesia resulted from posthypnotically triggered disinhibited feedback. However, their results seem equally consistent with a model that proposes disruption of lowlevel integration. One shortcoming of both mechanistic proposals for synesthesia induced post hypnosis is that they do not explain why the condition tends to endure much longer than drug-induced synesthesia.

A further interesting question is whether the above model could be adapted to explain acquired synesthesia in which necrosis leads to neurotransmitter flooding and elevated local serotonin levels. Though we do not have enough data on acquired synesthesia to make any firm conclusions at this point, it remains a possibility that some forms of developmental synesthesia are acquired in childhood in the same way as the persistent cases of acquired synesthesia, whereas temporarily acquired synesthesia is mechanistically akin to drug-induced synesthesia. If this is correct, then we should expect drug-induced synesthesia and temporarily acquired synesthesia to both lack systematicity, as they would result from pairing features with random information. We should furthermore expect persisting forms of acquired synesthesia to have the same patterns of permanence and systematicity as at least some forms of developmental synesthesia.

\section{DEVELOPMENTAL SYNESTHESIA IN AUTISTIC AND NON-AUTISTIC INDIVIDUALS}

Though it is difficult to say whether alterations in the serotonergic system play a role in the development of the most common forms developmental synesthesia, such as week-color and graphemecolor, developmental synesthesia seen in autism spectrum disorder is plausibly triggered by unilateral changes in the serotonergic system (Milner, 1973; Chugani et al., 1997; DeLong, 1999). There is not yet any solid evidence that autism and synesthesia are mechanistically related but there appears to be a statistical correlation as well as a possible genetic connection between the two conditions: synesthesia as well as sensory and perceptual abnormalities, such as hyper-responsiveness to sensory stimulation, are often reported as significant symptoms in autism-spectrum disorders (Ornitz et al., 1978; Grandin, 1995; Kemner et al., 1995; Harrison and Hare, 2004; Asher et al., 2009; Baron-Cohen et al., 2009). Cytowic (1989) states that 15 percent of people with autism experience synesthesia, which would be significant compared to the 4.4 percent of the general population (Simner et al., 2006). However, a systematic population study of the correlation between autism and synesthesia has not yet been completed. About 10 percent of individuals with autism also have savant syndrome, and all three conditions have frequently been reported to occur together (Baron-Cohen et al., 2007; Bor et al., 2007; Rothen et al., 2012). Recently, a genetic link between synesthesia and autism was suggested (Asher et al., 2009). Despite the lack of solid evidence for a mechanistic connection between autism and synesthesia, the existing statistical and genetic correlations give us reason to explore how serotonin may be related to synesthesia in autistic individuals. I will look at the evidence for the serotonin hypothesis for autism and then propose some testable predictions about how serotonin may give rise to synesthesia in autistic individuals.

The evidence that serotonin plays a crucial role in autism is overwhelming. About 30 percent of autistic individuals have a 25 to 70 percent increase in blood levels of serotonin, also known as hyperserotonemia (Schain and Freedman, 1961; Chugani et al., 1997, 1999; Veenstra-VanderWeele et al., 2012). Hyperserotonemia has also been found to a similar degree in first-degree healthy relatives (Leboyer et al., 1999). As serotonin cannot normally cross the blood-brain barrier in adults, high blood levels of serotonin are not necessarily a good indicator of high extracellular serotonin in the brain. High blood levels of serotonin, however, may indicate brain levels of serotonin in young children, as the blood-brain barrier is not fully developed until the age of two. Higher rates of autism have also been found in children exposed in utero to drugs that increase 5-HT levels, such as cocaine (Kramer et al., 1994). The high levels of serotonin in young children can negatively affect the development of serotonin neurons through negative feedback. As serotonin neurons develop and the extracellular levels of the neurotransmitter increase, growth of serotonin neurons is normally curtailed through a negative feedback mechanism, leading to a loss of serotonin terminals (DeLong, 1999; Whitaker-Azmitia, 2005). This decrease in serotonin terminal development has also been found in animal studies administering monoamine oxidase $\mathrm{A}$ and $\mathrm{B}$ inhibitors or serotonin reuptake inhibitors during gestation (Whitaker-Azmitia et al., 1994). 
Several PET imaging studies have suggested that autism may be a lateralized syndrome, with decreased serotonin release from raphe terminals in one hemisphere (typically the left) and elevated serotonin release in the contralateral hemisphere (Chugani et al., 1997, 1999; Chandana et al., 2005). Significantly increased language impairment was found in subjects with decreased serotonin synthesis in the left hemisphere compared to individuals with right-hemisphere abnormalities and those without cortical asymmetry. Further evidence for the lateralization theory comes from studies indicating functional improvement with selective serotonin reuptake inhibitors (SSRIs), such fluoxetine (DeLong, 1999). SSRIs block serotonin transporters, preventing extracellular serotonin from being transported back into the cell. When children with autism are treated with SSRIs, the symptoms they share in common with individuals with major depressive disorder and anxiety disorders drastically improve. The children's range of interests broaden, their perceptual experiences normalize, their memory and cognitive functions improve and anxiety and phobias become less prominent. Depleting brain serotonin in a tryptophan depletion paradigm, on the other hand, results in a worsening of the mood-related symptoms of autism as well as behaviors such as whirling, flapping, rocking and pacing (McDougle et al., 1996), though it does not affect the other symptoms of autism.

One possible explanation of the asymmetry is that the early serotonin depletion in the dominant left hemisphere leads to overcompensation in the right hemisphere. It has been reported that a decrease in extracellular serotonin over time may lead to an excessive spread of thalamocortical axon branches, resulting in lower information-transmission and structural changes in affected cortical regions as well as underdeveloped long-range connections between different brain areas (DeLong, 1999; Mueller et al., 2013). When the decrease in serotonin is left-lateralized, this leads to a general hypoexcitability of the left hemisphere and a wider right parietooccipital region compared to individuals with mental retardation or miscellaneous neurological disorders (Hier etal., 1979). The reversal of the asymmetry may be the result of initial right-hemisphere dominance, as indicated by a higher incidence of left-handedness and improved language skills in autistic individuals with decreased serotonin synthesis in the right hemisphere (Chandana et al., 2005). These results may explain why savant syndrome occurs in ten percent of autistic individuals. The leading hypothesis is that savant syndrome is caused by a lesion or birth defect in one hemisphere that results in overcompensation by the other hemisphere (Pesenti et al., 2001; Snyder et al., 2003; Young et al., 2004; Treffert, 2009; Loui et al., 2011).

A hemispheric effect does not provide clear evidence for a role of serotonin in synesthesia, as not all individuals with autism have synesthesia. But the expected high frequency of synesthesia in autistic individuals together with the lateralization hypothesis point to the possibility that increased extracellular levels of serotonin in the autistic brain may be a causal influence on the genesis of synesthesia in individuals with this disorder. There appears to be two ways in which serotonin could be implicated in synesthesia in autistic individuals. One possibility is that the high serotonin levels in very young children with autism sometimes trigger altered multisensory processing. Another possibility is that compensatory high serotonin levels in the contralesional hemisphere sometimes cause unusual feature binding. If the former hypothesis is correct, then we should expect to find evidence of synesthesia in autistic individuals at a very young age.

There are multiple ways that elevated serotonin levels may lead to synesthesia in autistic individuals. If the onset of synesthesia in autism occurs at an early age, it could be the result of serotonintriggered hyperactivity in glutamatergic neurons in layer $\mathrm{V}$ and resulting destabilization of thalamic connections. If this hypothesis is correct for synesthesia in autistic individuals, then we should expect that the synesthetic connections can persist only in the form of tight memory connections after the subsequent loss of serotonin-terminals in large areas of the brain. Accordingly, on the assumption that projector synesthesia is not normally mnemonic, we should not expect to find a significant number of projector synesthetes among autistic individuals. Another way synesthetic connections could form would be through the early excessive formation of neural pathways. Persisting synesthesia in this case would require that the early formed structural connections could survive the extensive pruning that appears to take place when serotonin-terminals are lost. If the onset of the synesthesia does not occur at an early age, structural or functional synesthetic connections could still form in the spared right-hemisphere regions that are also believed to be responsible for the savant skills founds in 10 percent of autistic individuals. Structural connectivity mechanisms have been proposed for standard cases of grapheme-color synesthesia, suggesting unusual connectivity between the color area and the fusiform gyrus (Ramachandran and Hubbard, 2001a,b; Hubbard et al., 2005). Enhanced anatomical connectivity near the fusiform gyrus confirming this hypothesis has been reported for grapheme-color synesthesia (Rouw and Scholte, 2007; Jancke et al., 2009; Hanggi et al., 2011) and sound-color synesthesia (Zamm et al., 2013). Whether a structural connectivity mechanism also underlies synesthesia in autism could fairly easily be tested by using a DTI paradigm to look at whether there are similar patterns of localized hyper-corticalconnectivity in autistic individuals with synesthesia. If the onset of the synesthesia does not occur at an early age, there is also the possibility that it is the result of impaired higher-order multisensory integration associated with decreased functional and structural connectivity (Mueller et al., 2013). This would make developmental synesthesia in autism very different from other cases, which appear to be a result of increased structural or functional connectivity. There is, however, a fairly strong reason against this mechanism as explanatory of synesthesia in autistic individuals. Impaired multisensory integration in autism amounts to a failure to associate two high-level sensory input that neurotypical individuals would associate (Mueller et al., 2013), not a persistent success in associating two input that neurotypical individuals do not associate.

Whether a hyperactive serotonergic system can contribute to developmental synesthesia in non-autistic individuals is unknown. As autism is partly defined by sensory processing deficits, the emergence of synesthesia in autism could be a consequence of other sensory alterations and originate from a unique set of 
mechanisms distinct from those present in other cases of developmental synesthesia. But some data points indicate that serotonin may be mechanistically involved in producing synesthetic experience through altered functional connectivity. As Brang and Ramachandran (2007) observed, there is some reported pharmacological evidence suggesting that developmental synesthesia in non-autistic individuals could sometimes be a serotonergic condition. Pharmacological evidence for the serotonin hypothesis was also reported by Cytowic (1989). He describes a patient with life-long synesthesia who developed epilepsy as an adult and subsequently experienced less vivid synesthetic experiences when treated with the anti-epileptic drug Tegretol (carbamazepine), which is known to increase extracellular levels of serotonin (Cytowic, 1989, p. 174). The reports from Cytowic (1989) and Brang and Ramachandran (2007) may seem to provide evidence against serotonin triggering synesthesia via excitatory activity, as the increased serotonin levels apparently inhibited synesthesia. However, both fluoxetine and carbamazepine have been shown to significantly increase GABA and reduce glutamate levels, which would block the excitatory effects of serotonin in cortical areas (Kamal, 2010). So, these data suggest that serotonin may be functionally involved in generating synesthetic experience either through a disinhibited feedback mechanism or by making unusual structural binding available for conscious processing. The pharmacological evidence thus lends some support to a disinhibited feedback mechanism, which suggests that synesthesia is not a result of altered structural connectivity but arises from altered functional feedback connections. This type of mechanism has received prior support from psychophysical and neuromagining studies of non-autistic synesthetes (Grossenbacher and Lovelace, 2001; Dixon et al., 2006; Esterman et al., 2006; Neufeld et al., 2012). A recent imaging study of 14 auditory-visual non-autistic synesthetes, for example, found increased functional connectivity of the left inferior parietal cortex with the left primary auditory and right primary visual cortex (Neufeld et al., 2012), suggesting that the aberrant synesthetic binding takes place in parietal cortex. There is also suggestive evidence of mixed mechanisms. For example, some forms of grapheme-color synesthesia appear to involve enhanced visual memory associations with hyper-reinstantiation in the visual cortex (see Brogaard, 2013 and Brogaard et al., 2013 for reviews).

Drawing on evidence that the 5-HT2A receptor may be involved in generating synesthetic experience, Brang and Ramachandran (2007) suggest that synesthesia might occur from overexpression of the 5-HT2A receptor gene on chromosome 13. A whole-genome linkage scan and a family-linkage analysis in a sample of 43 multiplex families with auditory-visual synesthesia did not confirm this hypothesis (Asher et al., 2009). Instead the study suggested that synesthesia may be traceable to a region on chromosome 2 (2q24.1) that has been implicated in autism (Newbury et al., 2009), indicating that there may be genetic link between developmental synesthesia and autism.

Other evidence gives some credit to the hypothesis that synesthesia in non-autistic individuals could be related in terms of brain structure to autism and savant syndrome and hence that a particular brain structure may underlie all of these conditions.
Population studies suggest that there may be a higher incidence of synesthesia among people with creative talent (Domino, 1989; Mulvenna and Walsh, 2005; Simner et al., 2006; Rothen and Meier, 2010). Conversely, some synesthetes appear to have greater cognitive and memory capacities specific to the concurrent of the individual's synesthesia compared to the general population (Yaro and Ward, 2007; Ward et al., 2008; Banissy et al., 2009; Rothen et al., 2012). The possible association between synesthesia and cognitive talent might suggest that synesthetes without autism have serotonin-induced hyperconnected neural networks without the down-regulated neural regions found in people with autism. Recent neuroimaging studies further point to enhanced functional connectivity or increased gray matter density in synesthesia. A recent functional MRI study found increased intrinsic network connectivity in 12 grapheme-color synesthetes that reflected the strength of their synesthetic experiences (Dovern etal., 2012). Wiess and Fink (2009) further reported greater gray matter volume in the left intraparietal sulcus and right fusiform gyrus in 18 synesthetes compared to 18 controls. Several DTI studies have confirmed increased white matter connections in the superior parietal cortex, right inferior temporal cortex and frontal regions in grapheme-color synesthesia (Rouw and Scholte, 2007; Jancke et al., 2009, though at more liberal thresholds; Hanggi et al., 2011) and sound-color synesthesia (Zamm et al., 2013). Although these lines of evidence do not provide evidence of a causal connection among developmental synesthesia, autism and savant syndrome, results are suggestive that local hyperconnectivity is a common feature of these conditions.

However, we do not yet have enough data to draw any firm conclusions about the role of serotonin in developmental synesthesia in non-autistic individuals or the connection between developmental synesthesia and autism. More systematic population studies as well as whole-genome linkage scans and family linkage analyses may be able to shed more light on this connection. The extent to which serotonin is mechanistically involved in developmental synesthesia could be tested more systematically in pharmacological studies using drugs known to inhibit 5-HT2A receptors, such as SSRIs (Brang and Ramachandran, 2007), and serotonin-agonists, such as cocaine, that are only reported to cause hallucinations with excessive use. If serotonin is functionally implicated in synesthesia, we should expect 5-HT2A inhibitors to block or reduce synesthesia and serotonin-agonists to augment the experiences. A negative result would rule out that serotonin is functionally involved in synesthesia but would leave open the possibility that the neurotransmitter is involved in the onset of developmental synesthesia by leading to an early change in structural connectivity.

\section{CONCLUSION}

The primary aim here has been to defend the hypothesis that synesthesia is at least sometimes a hyperserotonergic condition that triggers synesthesia through excitatory neurotransmitter action. The main evidence in favor of this hypothesis can be summarized as follows:

First of all, brain injury that gives rise to acquired synesthesia leads to necrosis and excessive release of serotonin and glutamate. 
Though this increase in excitatory neurotransmitter activity leads to lower excitability in local areas through negative feedback within weeks, decreased activity in affected neural regions could lead to a disinhibitory enhancement of neural activity and connectivity in unaffected cortical regions. Alternatively, the early increase in serotonin levels could lead to the formation of unusual feature binding.

Secondly, administration of certain hallucinogenic serotonin agonists (e.g., psilocybin) induces synesthesia. The mechanism underlying drug-induced synesthesia plausibly involves

\section{REFERENCES}

Abraham, H. D. (1983). Visual phenomenology of the LSD flashback. Arch. Gen. Psychiatry 40, 884889. doi: 10.1001/archpsyc. 1983 . 01790070074009

Afra, P., Funke, M., and Matuso, F. (2009). Acquired auditory-visual synesthesia: a window to early crossmodal sensory interactions. Psychol. Res. Behav. Manag. 2, 31-37. doi: 10.2147/PRBM.S4481

Aghajanian, G. K., and Marek, G. J. (1999). Serotonin induces excitatory postsynaptic potentials in apical dendrites of neocortical pyramidal cells. Neuropharmacology 36, 589-599. doi: 10.1016/S0028-3908(97)00051-8

Alstadhaug, K. B., and Benjaminsen, E. (2010). Synesthesia and migraine: case report. BMC Neurol. 10:121. doi: 10.1186/1471-2377-10-121

Armel, K. C., and Ramachandran, V. S. (1999). Acquired synesthesia in Retinitis Pigmentosa. Neurocase 5, 293-296. doi: 10.1080/ 13554799908411982

Asher, J. E., Lamb, J. A., Brocklebank, D., Cazier, J. B., Maestrini, E., Addis, L., etal. (2009). A whole-genome scan and finemapping linkage study of auditoryvisual synesthesia reveals evidence of linkage to chromosomes 2q24, 5q33, $6 \mathrm{p} 12$, and 12p12. Am. J. Hum. Genet. 84, 1-7. doi: 10.1016/j.ajhg.2009. 01.012

Banissy, M. J., Walsh, V., and Ward, J. (2009). Enhanced sensory perception in synaesthesia. Exp. Brain Res. 196, 565-571. doi: 10.1007/s00221009-1888-0

Barkai, E., and Hasselmo, M. E. (1994). Modulation of the input/output function of rat piriform cortex pyramidal cells. J. Neurophysiol. 72, 644 658.

Baron-Cohen, S., Ashwin, E., Ashwin, C., Tavassoli, T., and Chakrabarti, B. (2009). Talent in autism: hypersystemizing, hyper-attention to detail and sensory hypersensitivity. Philos. Trans. R. Soc. Lond. B Biol. Sci. 364, 1377-1383 doi: 10.1098/rstb.2008. 0337
Baron-Cohen, S., Bor, D., Billington, J., Asher, J. E., Wheelwright, S., and Ashwin, C. (2007). Savant memory in a man with colour form-number synaesthesia and Asperger syndrome. J. Conscious. Stud. 14, 237-251.

Baron-Cohen, S., Burt, L., SmithLaittan, F., Harrison, J., and Bolton, P. (1996). Synaesthesia: prevalence and familiality. Perception 25, 1073-1079. doi: 10.1068/p251073

Baron-Cohen, S., Wyke, M., and Binnie, C. (1987). Hearing words and seeing colors: an experimental investigation of synesthesia. Perception 16, 761-767. doi: 10.1068/p160761

Beauchamp, M. S., and Ro, T. (2008) Neural substrates of sound-touch synesthesia following a thalamic lesion. J. Neurosci. 28, 1369613702. doi: 10.1523/JNEUROSCI. 3872-08.2008

Behrendt, R. P., and Young, C. (2004) Hallucinations in schizophrenia, sensory impairment, and brain disease: a unifying model. Behav. Brain Sci. 27, 771-787. doi: 10.1017/S0140525X04000184

Bor, D., Billington, J., and BaronCohen, S. (2007). Savant memory for digits in a case of synaesthesia and Asperger syndrome is related to hyperactivity in the lateral prefrontal cortex. Neurocase 13, 311-319. doi: 10.1080/13554790701844945

Brang, D., and Ramachandran, V. S. (2007). Psychopharmacology of synesthesia; the role of serotonin S2a receptor activation. Med. Hypotheses 70, 903-904. doi: 10.1016/j.mehy.2007.09.007

Brang, D., and Ramachandran, V. S. (2011). Survival of the synesthesia gene: why do people hear colors and taste words? PLoS Biol. 9:e1001205. doi: 10.1371/journal. pbio. 1001205

Brogaard, B. (2012). "Color synesthesia," in Cognition and Language, Encyclopedia of Color Science and Technology, ed. K. A. Jameson (Berlin: Springer), (in press).

Brogaard, B. (2013). "Synesthetic binding and the reactivation model of memory," in Sensory Blendings: New

serotonergic excitatory activity in layer $\mathrm{V}$ pyramidal neurons implicated in multisensory binding.

Thirdly, serotonin synthesis is typically increased unilaterally in individuals with autism, about 15 percent of which are believed to experience synesthesia compared to about 4 percent population-wide. In terms of a potential mechanism, one possibility is that serotonin causes aberrant structural binding in the spared neural regions that are also responsible for the savant skills found in 10 percent of autistic individuals.

Essays on Synaesthesia, O. Deroy and M. Nudds (Oxford: Oxford University Press), (in press).

Brogaard, B., and Marlow, K. (2013). From brain damage to beethoven. How a head injury created a musical prodigy. Guru Mag. 11, 10-14.

Brogaard, B., Marlow, K., and Rice, K. (2013). “The long-term potentiation model for grapheme-color binding in synesthesia," in Sensory Integration and the Unity of Consciousness, eds D. Bennett and C. Hill (Cambridge: MIT Press), (in press).

Brogaard, B., Vanni, S., and Silvanto, J. (2012). Seeing mathematics: perceptual experience and brain activity in acquired synesthesia. Neurocase doi: 10.1080/13554794.2012.701646 [Epub ahead of print].

Bullock, R., Zauner, A., Woodward, J. J., Myseros, J., Choi, S. C., Ward, J. D., et al. (1998). Factors affecting excitatory amino acid release following severe human head injury. J. Neurosurg. 89, 507-518. doi: 10.3171/jns.1998.89.4.0507

Busto, R., Dietrich, W. D., Globus, M. Y., Alonso, O., and Ginsberg, M. D. (1997). Extracellular release of serotonin following fluid-percussion brain injury in rats. J. Neurotrauma 14, 35-42. doi: 10.1089/neu.1997. 14.35

Carhart-Harris, R. L., Erritzoe, D., Williams, T., Stone, J. M., Reed, L. J., Colasanti, A., et al. (2012). Neural correlates of the psychedelic state as determined by fMRI studies with psilocybin. Proc. Natl. Acad. Sci. U.S.A. 109, 2138-2143 doi: 10.1073/pnas.1119598109

Ceglia, I., Carli, M., Baviera, M. Renoldi, G., Calcagno, E., and Invernizzi, R. W. (2004). The 5-HT receptor antagonist M100, 907 prevents extracellular glutamate rising in response to NMDA receptor blockade in the mPFC. J. Neurochem. 91, 189-199. doi: 10.1111/j.14714159.2004.02704.x

Chandana, S. R., Behen, M. E., Juhasz, C., Muzik, O., Rothermel, R. D., Mangner, T. J., et al. (2005). Significance of abnormalities in develop-mental trajectory and asymmetry of cortical serotonin synthesis in autism. Int. J. Dev. Neurosci. 23, 171-182 doi: 10.1016/j.ijdevneu.2004.08.002

Chugani, D. C., Muzik, O., Behen, M., Rothermel, R., Janisse, J. J., Lee, J., et al. (1999). Developmental changes in brain serotonin synthesis capacity in autistic and nonautistic children. Ann. Neurol. 45, 287-295. doi: 10.1002/15318249(199903)45:3<287::AID-ANA 3>3.0.CO;2-9

Chugani, D. C., Muzik, O., Rothermel, R., Behen, M., Chakraborty, P., Mangner, T., et al. (1997). Altered serotonin synthesis in the dentatothalamocortical pathway in autistic boys. Ann. Neurol. 42, 666-669. doi: 10.1002/ana. 410420420

Ciranna, L. (2006). Serotonin as a modulator of glutamate- and GABAmediated neurotransmission: implications in physiological functions and in pathology. Curr. Neuropharmacol. 4, 101-114. doi: 10.2174/ 157015906776359540

Cohen Kadosh, R., Henik, A., Catena, A., Walsh, V., and Fuentes, L. J. (2009). Induced cross-modal synaesthetic experience without abnormal neuronal connections. Psychol. Sci. 20, 258-265. doi: 10.1111/j.14679280.2009.02286.x

Cott, C., and Rock, A. (2008). Phenomenology of N,N-dimethyltryptamine use: a thematic analysis. J. Sci. Explor. 22, 359-370.

Cytowic, R. E. (1989). Synesthesia: A Union of the Senses. New York: Springer Verlag. doi: 10.1007/978-14612-3542-2

Cytowic, R. E. (1997). "Synaesthesia: phenomenology and neuropsychology - a review of current knowledge," in Synaesthesia: Classic and Contemporary Readings, eds S. Baron-Cohen and J. E. Harrison (Oxford: Blackwell), 17-39.

DeLong, G. R. (1999). Autism: new data suggest a new hypothesis. Neurology 52, 911-916. doi: 10.1212/WNL.52.5.911 
Devinsky, O., and Luciano, D. (1991). Psychic phenomena in partial seizures. Sem. Neurol. 11, 100-109. doi: 10.1055/s-2008-1041211

Dixon, M. J., Smilek, D., Duffy, P. L., Zanna, M. P., and Merikle, P. M. (2006). The role of meaning in grapheme-colour synaesthesia. Cortex 42, 243-252. doi: 10.1016/S00109452(08)70349-6

Dixon, M. J., Smilek, D., and Merikle, P. M. (2004). Not all synaesthetes are created equal: projector versus associator synaesthetes. Cogn. Affect. Behav. Neurosci. 4, 335-343. doi: 10.3758/CABN.4.3.335

Domino, G. (1989). Synaesthesia and creativity in fine arts students: an empirical look. Creat. Res. J. 2, 17-29. doi: 10.1080/10400418909534297

Dorman, C. (1991). Exceptional calendar calculating ability after early left hemispherectomy. Brain Cogn. 15, 26-36. doi: 10.1016/02782626(91)90013-X

Dovern, A., Fink, G. R., Fromme, A. C., Wohlschläger, A. M., Weiss, P. H., and Riedl, V. (2012). Intrinsic network connectivity reflects consistency of synesthetic experiences. J. Neurosci. 32, 7614-7621. doi 10.1523/JNEUROSCI.5401-11.2012

Eagleman, D. M., Kagan, A. D., Nelson, S. S., Sagaram, D., and Sarma, A. K. (2007). A standardized test battery for the study of Synesthesia. $J$. Neurosci. Methods 159, 139-145. doi: 10.1016/j.jneumeth.2006.07.012

Esterman, M., Verstynen, T., Ivry, R. B., and Robertson, L. C. (2006). Coming unbound: disrupting automatic integration of synesthetic color and graphemes by transcranial magnetic stimulation of the right parietal lobe. J. Cogn. Neurosci. 18, 1570-1576. doi 10.1162/jocn.2006.18.9.1570

Eysel, U. T., Schweigart, G., Mittmann, T., Eyding, D., Qu, Y., Vandesande, F., et al. (1999). Reorganization in the visual cortex after retinal and cortical damage. Restor. Neurol. Neurosci. 15, 153-164.

Fay, L. (1987). That smarts! Accident leaves man with unforgettable gift. Virginia Pilot 31-33.

Ffytche, D. H. (2007). Visual hallucinatory syndromes: past, present, and future. Dialog. Clin. Neurosci. 9, 173-189.

Friedrichs, H. (2009). Die Psychologie des Meskalinrausches. Berlin: Verlag für Wissenschaft und Bildung.

Giza, C. C., and Prins, M. L. (2006). Is being plastic fantastic? Mechanisms of altered plasticity after developmental traumatic brain injury. Dev. Neurosci. 28, 364-379. doi $10.1159 / 000094163$
Glennon, R. A. (1990). Do classical hallucinogens act as 5-HT2 agonists or antagonists? Neuropsychopharmacology 3, 509-517.

González-Maeso, J., Ang, R. L., Yuen, T., Chan, P., Weisstaub, N. V., LópezGiménez, J. F., et al. (2008). Identification of a serotonin/glutamate receptor complex implicated in psychosis. Nature 452, 93-97. doi: 10.1038/nature06612

González-Maeso, J., Weisstaub, N. V., Zhou, M., Chan, P., Ivic, L., Ang, R. et al. (2007). Hallucinogens recruit specific cortical 5-HT2A receptormediated signaling pathways to affect behavior. Neuron 53, 439-452. doi: 10.1016/j.neuron.2007.01.008

Grossenbacher, P. G., and Lovelace, C. T. (2001). Mechanisms of synesthesia: cognitive and physiological constraints. Trends Cogn. Sci. 5, 36-41. doi: 10.1016/S1364-6613(00) 01571-0

Grandin, T. (1995). Thinking in Pictures: My life with Autism. New York: Doubleday.

Guillery, R. W., and Harting, J. K. (2003). Structure and connections of the thalamic reticular nucleus: advancing views over half a century. J. Comp. Neurol. 463, 360-71 doi: 10.1002/cne.10738

Hanggi, J., Wotruba, D., and Jäncke, L. (2011). Globally altered structural brain network topology in grapheme-color synesthesia. J. Neurosci. 31, 5816-5828 doi: 10.1523/JNEUROSCI.0964-10.2011

Harrison, J., and Hare, D. J. (2004). Brief report: assessment of sensory abnormalities in people with autistic spectrum disorders. J. Autism Dev. Disord. 34, 727-730 doi: 10.1007/s10803004-5293-z

Hier, D. B., LeMay, M., and Rosenberger, P. B. (1979). Autism and unfavorable left-right asymmetries of the brain. $J$. Autism Dev. Disord. 9, 153-159. doi: 10.1007/BF01531531

Hintzen, A., and Passie, T. (2010). The Pharmacology of LSD. Oxford, New York: Oxford University Press.

Hinzman, J. M., Thomas, T. C., Burmeister, J. J., Quintero, J. E., Huettl, P., Pomerleau, F, et al. (2010). Diffuse brain injury elevates tonic glutamate levels and potassium-evoked glutamate release in discrete brain regions at two days post-injury: an enzymebased microelectrode array study. J. Neurotrauma 27, 889-899. doi: 10.1089/neu.2009.1238

Hubbard, E. M. (2007). Neurophysiology of synesthesia. Curr. Psychiatry Rep. 9, 193-199. doi: 10.1007/s11920-007-0018-6
Hubbard, E. M., Manohar, S., and Ramachandran, V. S. (2005). Contrast affects the strength of synesthetic colors. Cortex 184-194.

Jacobs, L., Karpik, A., and Bozian, D. (1981). Auditory-visual synesthesia: sound-induced photism. Arch. Neurol. 38, 211-216. doi: 10.1001/archneur. 1981.00510040037005

Jacome, E., and Gumnit, R. J. (1979). Audioalgesic and audiovisuoalgesic synesthesias: epileptic manifestation. Neurology 29, 1050-1053. doi: 10.1212/WNL.29.7.1050

Jancke, L., Beeli, G., Eulig, C., and Hanggi, J. (2009). The neuroanatomy of grapheme-color synesthesia. Eur. J. Neurosci. 29, 1287-1293. doi: 10.1111/j.1460-9568.2009.06673.x

Kamal, S. M. (2010). Pharmacological modulation of brain levels of glutamate and GABA in rats exposed to total sleep deprivation. J. Exp. Pharmacol. 2, 65-71. doi 10.2147/JEP.S11143

Kemner, C., Verbaten, M. N., Cuperus, J. M., Camfferman, G., and van Engeland, H. (1995). Auditory eventrelated brain potentials in autistic children and three different control groups. Biol. Psychiatry 38, 150165. doi: 10.1016/0006-3223(94) 00247-Z

Kim, U., and McCormick, D. A. (1998) The functional influence of burst and tonic firing mode on synaptic interactions in the thalamus. J. Neurosci. 18, 9500-9516.

Kometer, M., Schmidt, A., Jäncke, L., and Vollenweider, F. X. (2013). Activation of serotonin $2 \mathrm{~A}$ receptors underlies the psilocybininduced effects on oscillations, N170 visual-evoked potentials, and visual hallucinations. $J$ Neurosci. 33, 10544-10551 doi: 10.1523/JNEUROSCI.3007-12.2013

Kramer, K., Azmitia, E. C., and Whitaker-Azmitia, P. M. (1994). In vitro release of $[3 \mathrm{H}] 5$ hydroxytryptamine from fetal and maternal brain by drugs of abuse Brain Res. Dev. 78, 142-146. doi 10.1016/0165-3806(94)90019-1

Klimesch, W. (2011). Evoked and early access to the knowledge system: the P1 inhibition timing hypothesis. Brain Res. 1408, 52-71. doi: 10.1016/j.brainres.2011.06.003

Konrad, C., Geburek, A. J., Rist, F., Blumenroth, H., Fischer, B., Husstedt I., et al. (2011). Long-term cognitive and emotional consequences of mild traumatic brain injury. Psychol. Med. 41, 1197-1211. doi: 10.1017/S0033291710001728

Leboyer, M., Philippe, A., Bouvard, M., Guilloud-Bataille, M.
Bondoux, D., Tabuteau, F., etal. (1999). Whole blood serotonin and plasma beta-endorphin in autistic probands and their first-degree relatives. Biol. Psychiatry 45, 158163. doi: 10.1016/S0006-3223(97) 00532-5

Lee, H.-M., and Roth, B. L. (2012). Hallucinogen actions on human brain revealed. Proc. Natl. Acad. Sci. U.S.A. 109, 1820-1821. doi: 10.1073/pnas.1121358109

Lessell, S., and Cohen, M. M. (1979). Phosphenes induced by sound. Neurology 29, 1524-1526. doi: 10.1212/WNL.29.11.1524

Loui, P., Li, H. C., Hohmann, A., and Schlaug, G. (2011). Enhanced cortical connectivity in absolute pitch musicians: a model for local hyperconnectivity. J. Cogn. Neurosci. 23 , 1015-1026. doi: 10.1162/jocn.2010. 21500

Lythgoe, M., Pollak, T., Kalmas, M., de Hann, M., and Chong, W. K. (2005). Obsessive, prolific artistic output following subarachnoid hemorrhage. Neurology 64, 397-398. doi: $\quad$ 10.1212/01.WNL.0000150526. 09499.3E

Markram, H., Toledo-Rodriguez, M., Wang, Y., Gupta, A., Silberberg, G., and $\mathrm{Wu}, \mathrm{C}$. (2004). Interneurons of the neocortical inhibitory system. Nat. Rev. Neurosci. 5, 793-807. doi: 10.1038/nrn1519

Mattingley, J. B., Rich, A. N., Yelland, G., and Bradshaw, J. L. (2001). Unconscious priming eliminates automatic binding of colour and alphanumeric form in synaesthesia. Nature 410, 580-582. doi: 10.1038/ 35069062

McDougle, C. J., Naylor, S. T., Cohen, D. J., Aghajanian, G. K., Heninger, G. R., and Price, L. H. (1996). Effects of tryptophan depletion in drug-free adults with autistic disorder. Arch. Gen. Psychiatry 53, 993-1000. doi: 10.1001/archpsyc.1996.01830110029004

Miller, B., Boon, K., Cummings, J. L., Read, S. L., and Mishkin, F. (2000). Functional correlates of musical and visual ability in frontotemporal dementia. Br. J. Psychiatry 176, 458-463. doi: 10.1192/bjp.176.5.458 Miller, B. L., Cummings, J., Mishkin, F., Boone, K., Prince, F., Ponton, M., et al. (1998). Emergence of artistic talent in fronto-temporal dementia. Neurology 51, 978-982. doi: 10.1212/WNL.51.4.978

Milner, B. (1973). "Hemispheric specialization: scope and limits," in The Neurosciences: Third Study Program, eds F. O. Schmidt, F. G. Worden (Cambridge: MIT Press), 75-89. 
Mueller, S., Keeser, D., Samson, A. C., Kirsch, V., Blautzik, J., Grothe, M., et al. (2013). Convergent findings of altered functional and structural brain connectivity in individuals with high functioning autism: a multimodal MRI study. PLoS ONE 8:e67329. doi: 10.1371/journal.pone. 0067329

Mulvenna, C., and Walsh, V. (2005). Synaesthesia. Curr. Biol. 15, R399R400. doi: 10.1016/j.cub.2005.05.039 Neufeld, J., Sinke, C., Zedler, M., Dillo, W., Emrich, H. M., Bleich, S., et al. (2012). Disinhibited feedback as a cause of synesthesia: evidence from a functional connectivity study on auditory-visual synesthetes. $\mathrm{Neu}$ ropsychologia 50, 1471-1477. doi: 10. 1016/j.neuropsychologia.2012.02.032

Newbury, D. F., Warburton, P. C., Wilson, N., Bacchelli, E., Carone, S., Lamb, J. A., et al. (2009). Mapping of partially overlapping de novo deletions across an autism susceptibility region (AUTS5) in two unrelated individuals affected by developmental delays with communication impairment. Am. J. Med. Genet. A 149A, 588-597 doi: 10.1002/ajmg.a.32704

Nichols, D. E. (2004). Hallucinogens. Pharmacol. Ther. 101, 131181. doi: 10.1016/j.pharmthera.2003. 11.002

Ornitz, E. M., Guthrie., D., and Farley, A. J. (1978). “The early symptoms of childhood autism," in Cognitive Defects in the Development of Mental Illness, ed. G. Serban (New York: Brunner/Mazel), 24-42.

Perez-Polo, J. R., Rea, H. C., Johnson, K. M., Parsley, M. A., Unabia, G. C., Xu, G., et al. (2013). Inflammatory consequences in a rodent model of mild traumatic brain injury. J. Neurotrauma 30, 727-740. doi: 10.1089/neu.2012.2650

Pesenti, M., Zago, L., and Crivello, F. (2001). Mental calculation in a prodigy is sustained by right prefrontal and medial temporal areas. Nat. Neurosci. 4, 103-107. doi: 10.1038/82831

Pralong, E., Magistretti, P., and Stoop, R. (2002). Cellular perspectives on the glutamate-monoamine interactions in limbic lobe structures and their relevance for some psychiatric disorders. Prog. Neurobiol. 67, 173202. doi: 10.1016/S0301-0082(02) 00017-5

Presti, D., and Nichols, D. (2004). "Biochemistry and neuropharmacology of psilocybin mushrooms," in Teonanacatl: Sacred Mushroom of Vision, ed. R. Metzner (El Verano, CA: Four Trees), 89-108.
Previc, F. (2011). "Dopamine, altered consciousness, and distant space with special reference to shamanic ecstasy," in Altering Consciousness: A Multidisciplinary Perspective, Vol. 2. Biological and Psychological Perspectives, eds E. Cardeña and M. Winkelman (Westport, CT: Praeger), 43-61.

Ramachandran, V. S., and Hubbard, E. M. (2001a). Psychophysical investigations into the neural basis of synaesthesia. Proc. R. Soc. B Biol. Sci. 268, 979-983. doi: 10.1098/rspb.2001.1576

Ramachandran, V. S., and Hubbard, E. M. (2001b). Synaesthesia: a window into perception, thought and language. J. Conscious. Stud. 8, 3-34.

Rich, A. N., and Mattingley, J. B. (2002) Anomalous perception in synaesthesia: a cognitive neuroscience perspective. Nat. Rev. Neurosci. 3, 43-52. doi: 10.1038/nrn702

Ro, T., Ellmore, T. M., and Beauchamp, M. S. (2012). A neural link between feeling and hearing. Cereb. Cortex 23, 1724-1730. doi: 10.1093/cercor/bhs 166

Ro, T., Farne, A., Johnson, R. M., Weeden, V., Chu, Z., Wang, Z. J., et al. (2007). Feeling sound after a thalamic lesion. Ann. Neurol. 62, 433-441. doi: 10.1002/ana. 21219

Robertson, C. S., Bell, M. J., Kochanek, P. M., Adelson, P. D., Ruppel, R. A., Carcillo, J. A., et al. (2001). Increased adenosine in cerebrospinal fluid after severe traumatic brain injury in infants and children: association with severity of injury and excitotoxicity. Crit. Care Med. 29, 2287-3393. doi: 10.1097/00003246200112000-00009

Rogowska, A. (2011). Categorization of synaesthesia. Rev. Gen. Psychol. 15, 213-227. doi: 10.1037/a0024078

Rothen, N., and Meier, B. (2010). Higher prevalence of synaesthesia in art students. Perception 39, 718-720. doi: 10.1068/p6680

Rothen, N., Meier, B., and Ward, J. (2012). Enhanced memory ability: insights from synaesthesia. Neurosci. Biobehav. Rev. 36, 1952-1963. doi: 10.1016/j.neubiorev.2012.05.004

Rouw, R., and Scholte, H. S (2007). Increased structural connectivity in grapheme-color synesthesia. Nat. Neurosci. 10, 792-797. doi: 10.1038/nn1906

Sacks, O. (2012). Hallucinations. Toronto: Alfred A. Knopf.

Sagiv, N., Ilbeigi, A., and Ben-Tal, O. (2011). Reflections on synesthesia, perception, and cognition. Intellectica 55, 81-94.

Sagiv, N., and Ward, J. (2006) Crossmodal interactions: lessons from synesthesia. Prog. Brain Res. 155, 259-271. doi: 10.1016/S0079 6123(06)55015-0

Schain, R. J., and Freedman, D. X. (1961). Studies on 5-hydroxyindole metabolism in autistic and other mentally retarded children. J. Pediatr. 58, 315-320. doi: 10.1016/S00223476(61)80261-8

Schott, G. D. (2012). Pictures as a neurological tool: lessons from enhanced and emergent artistry in brain disease. Brain 135, 1947-1963. doi: 10.1093/brain/awr314

Schroeder, C. E., and Foxe, J. (2005) Multisensory contributions to lowlevel, 'unisensory' processing. Curr. Opin. Neurobiol. 15, 454-458. doi: 10.1016/j.conb.2005.06.008

Scruggs, J. L., Schmidt, D., and Deutch, A. Y. (2003). The hallucinogen 1-[2,5-dimethoxy4-iodophenyl]-2-aminopropane (DOI) increases cortical extracellular glutamate levels in rats. Neurosci. Lett. 346, 137-140. doi: 10.1016/S0304-3940(03)00547-0

Shanon, B. (2002). The Antipodes of the Mind. Oxford, NY: Oxford University Press.

Shanon, B. (2003). Three stories concerning synaesthesia - a commentary on the paper by Ramachandran and Hubbard. J. Conscious. Studies 10, 69-74.

Simner, J., Mulvenna, C., Sagiv, N., Tsakanikos, E., Witherby, S. A., Fraser, C., et al. (2006). Synaesthesia: the prevalence of atypical cross-modal experiences. Perception 35, 1024 1033. doi: 10.1068/p5469

Sinke, C., Halpern, J. H., Zedler, M. Neufeld, J., Emrich, H. M., and Passie, T. (2012). Genuine and druginduced synesthesia: a comparison. Conscious. Cogn. 21, 1419-1434. doi: 10.1016/j.concog.2012.03.009

Snyder, A. (2009). Explaining and inducing savant skills: privileged access to lower level, less-processed information. Philos. Trans. R. Soc. Lond. B Biol. Sci. 364, 1399-1405. doi: 10.1098/rstb.2008.0290

Snyder, A. W., Mulcahy, E., Taylor, J. L., Mitchell, D., Sachdev, P., and Gandevia, S. C. (2003). Savant-like skills exposed in normal people by suppressing the left fronto-temporal lobe. J. Integr. Neurosci. 2, 149-158. doi: $10.1142 / S 0219635203000287$

Takeuchi, N., Oouchida, Y., and Izumi, S.-I. (2012). Motor control and neural plasticity through interhemispheric interactions. $\mathrm{Neu}$ ral Plast. 2012, 823285. doi: $10.1155 / 2012 / 823285$

Tammet, D. (2006). Born on a Blue Day. Inside the Extraordinary Mind of an Autistic Savant. New York: Free Press.

Terhune, D. B., and Cohen Kadosh, R. (2012). "Synaesthesias," in Hallucinations: Research and Practice, eds J. D. Blom and I. E. C. Sommer (New York: Springer), 91-104. doi: 10.1007/978-1-4614-0959-5_7

Terhune, D. B., Tai, S., Cowey, A., Popescu, T., and Cohen Kadosh, R. (2011). Enhanced cortical excitability in grapheme-color synesthesia and its modulation. Curr. Biol. 21, 20062009. doi: 10.1016/j.cub.2011.10.032

Thomas-Anterion, C., Creac'h, C. Dionet, E., Borg, C., Extier, C., Faillenot, I., et al. (2010). De novo artistic activity following insular-SII ischemia. Pain 150, 121-127. doi: 10.1016/j.pain.2010.04.010

Tomson, S. N., Avidan, N., Lee, K., Sarma, A. K., Tushe, R., Milewicz, D. M., et al. (2011). The genetics of colored sequence synesthesia: suggestive evidence of linkage to $16 \mathrm{q}$ and genetic heterogeneity for the condition. Behav. Brain Res. 223, 48-52 doi: 10.1016/j.bbr.2011.03.071

Torres-Escalante, J. L., Barral, J. A., Ibarra-Villa, M. D., Perez-Burgos, A., Gongora-Alfaro, J. L., and Pineda, J. C. (2004). 5-HT1A, 5HT2, and GABAB receptors interact to modulate neurotransmitter release probability in layer $2 / 3$ somatosensory rat cortex as evaluated by the paired pulse protocol. J. Neurosci. Res. 78, 268-278. doi: 10.1002/jnr. 20247

Treffert, D. A. (2006). Extraordinary People: Understanding Savant Syndrome. New York: Ballantine Books.

Treffert, D. A. (2009). The savant syndrome: an extraordinary condition. A synopsis: past, present, future. Philos. Trans. R. Soc. B Biol. Sci. 27, 1351-1357.

Trudeau, L. E. (2004). Glutamate cotransmission as an emerging concept in monoamine neuron function. $J$. Psychiatry Neurosci. 29, 296-310.

Veenstra-VanderWeele, J., Muller, C. L., Iwamoto, H., Sauer, J. E., Owens, W. A., Shah, C. R., etal. (2012). Autism gene variant causes hyperserotonemia, serotonin receptor hypersensitivity, social impairment and repetitive behavior. Proc. Natl. Acad. Sci. U.S.A. 109, 5469-5474. doi: 10.1073/pnas.11123 45109

Vollenweider, F. X., Leenders, K. L., Scharfetter, C., Maguire, P., Stadelmann, O., Angst, J. (1997). Positron emission tomography and fluorodeoxyglucose studies of metabolic hyperfrontality and 
psychopathology in the psilocybin model of psychosis. Neuropsychopharmacology 16, 357-372. doi: 10.1016/S0893-133X(96)00246-1

Vollenweider, F. X., VollenweiderScherpenhuyzen, M. F. I., Bäbler, A., Vogel, H., and Hell, D. (1998). Psilocybin induces schizophrenia-like psychosis in humans via a serotonin2 agonist action. NeuroReport 9, 3897-3902. doi: 10.1097/00001756199812010-00024

Walsh, R. (2005). Can synaesthesia be cultivated?: indications from surveys of meditators. J. Conscious. Studies 12, 5-17.

Ward, J. (2013). Synesthesia. Annu. Rev. Psychol. 64, 4975. doi: 10.1146/annurev-psych113011-143840

Ward, J., Thompson-Lake, D., Ely, R., and Kaminski, F. (2008). Synaesthesia, creativity and art: what is the link? Br. J. Psychol. 99, 127-141. doi: 10.1348/000712607X 204164

Ward, J., and Wright, T. (2012). Sensory substitution as an artificially acquired synaesthesia. Neurosci. Biobehav. Rev. doi: 10.1016/i.neubiorev.2012.07.007 [Epub ahead of print].

Werner, C., and Engelhard, K. (2007). Pathophysiology of traumatic brain injury. $\mathrm{Br}$. J. Anaesth. 99, 4-9. doi: 10.1093/bja/ aem 131

Whitaker-Azmitia, P. M. (2005). Behavioral and cellular consequences of increasing serotonergic activity during brain development: a role in autism? Int. J. Dev. Neurosci. 23, 75-83. doi: 10.1016/j.ijdevneu.2004. 07.022

Whitaker-Azmitia, P. M., Zhang, X., and Clarke, C. (1994). Effects of gestational exposure to monoamine oxidase inhibitors in rats: preliminary behavioral and neurochemical studies. Neuropsychopharmacology 11 , 125-132. doi: 10.1038/npp.1994.42

Wiess, P. H., and Fink, G. R. (2009). Grapheme-colour synaesthetes show increased grey matter volumes of parietal and fusiform cortex. Brain 132, 65-70. doi: 10.1093/brain/awn304
Yaro, C., and Ward, J. (2007). Searching for shereshevskii: what is superior about the memory of synaesthetes? Q. J. Exp. Psychol. (Hove) 60, 681-695. doi: 10.1080/17470210600 785208

Young, R. L., Ridding, M. C., and Morrell, T. L. (2004). Switching skills by turning off part of the brain. Neurocase 10, 215222. doi: 10.1080/13554790490 495140

Yuan, J. (2009). Neuroprotective strategies targeting apoptotic and necrotic cell death for stroke. Apoptosis 14, 469-477. doi: 10.1007/s10495-0080304-8

Zamm, A., Schlaug, G., Eagleman, D. M., and Loui, P. (2013). Pathways to seeing music: enhanced structural connectivity in colored-music synesthesia. Neuroimage 74, 359 366. doi: 10.1016/j.neuroimage.2013 02.024

Conflict of Interest Statement: The author declares that the research was conducted in the absence of any commercial or financial relationships that could be construed as a potential conflict of interest.

Received: 19 July 2013; accepted: 21 September 2013; published online: 21 October 2013.

Citation: Brogaard B (2013) Serotonergic hyperactivity as a potential factor in developmental, acquired and druginduced synesthesia. Front. Hum. Neurosci. 7:657. doi: 10.3389/fnhum.2013. 00657

This article was submitted to the journal Frontiers in Human Neuroscience.

Copyright (c) 2013 Brogaard. This is an open-access article distributed under the terms of the Creative Commons Attribution License (CC BY). The use, distribution or reproduction in other forums is permitted, provided the original author(s) or licensor are credited and that the original publication in this journal is cited, in accordance with accepted academic practice. No use, distribution or reproduction is permitted which does not comply with these terms. 